\title{
Fast analysis of high heating value and elemental compositions of sorghum biomass using near-infrared spectroscopy
}

14 Abstract

${ }^{1}$ Department of Biological and Agricultural Engineering, Kansas State University, Manhattan,

${ }^{2}$ College of Mechanic and Electrical Engineering, Tarim University, Alar, Xinjiang 843300, P.R. KS 66506, USA

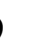

(1)

1
*Corresponding author. Telephone: 785-5322919, Fax: 785-5325825. E-mail: dwang@ksu.edu. ${ }^{3}$ Department of Chemistry, New York University, New York, NY 10003, USA ${ }^{4}$ Department of Agronomy, Iowa State University, Ames, IA 50011, USA

$$
\text { Near-infrared spectroscopy (NIR) is an efficient, low-cost sensing technology that has }
$$

17 develop NIR models in conjunction with chemometrics to determine high heating value (HHV)

18 and elemental compositions of sorghum biomass. Partial least squares (PLS) regression and

19 principle component regression (PCR) were used to develop calibration models with full and

20 reduced wavelength regions. In general, models from reduced wavelength regions yielded higher

21 calibration and prediction accuracies. Models to predict HHV, carbon, hydrogen, nitrogen, sulfur,

22 and oxygen contents of sorghum biomass were well developed. HHV value, carbon, hydrogen,

23 nitrogen, sulfur, and oxygen contents were predicted with $\mathrm{R}^{2}$ of $0.96,0.96,0.87,0.86,0.84$, and

240.83 for validation sample sets, respectively. HHV and carbon content models had excellent

25 prediction accuracy, whereas hydrogen, nitrogen, sulfur and oxygen models could provide

26 reliable predictions. Those models provide good insight into the relationship between chemical 
27 bonds and HHV and elemental composition of sorghum biomass, allowing a rapid and accurate 28 determination of HHV and elemental composition at low cost (from 200 to 1 USD) and reduced 29 the time (from 100 to $1 \mathrm{~min}$ ).

30

31 Keywords: sorghum; heating value; elemental composition analysis; near-infrared; chemometric 32 analysis 


\section{Introduction}

35 Renewable energy derived from biomass is an desirable alternative to conventional fossil fuel

36 because biomass is abundant and has no negative impact on the environment [1]. Sorghum is a

37 favorable feedstock for biofuel production because of its high yield efficiency and high tolerance

38 to drought [2]; furthermore, sorghum yield ranks third among cereal crops in the Midwest region

39 of the United States [3]. Efficiency of biomass utilization for biofuel significantly depends on

40 physical and chemical properties, which vary according to plant species, growing environments,

41 harvest times, and storage conditions [4]. Recently, some biomass utilization have been directly

42 related to energy production, such as thermal application for greenhouse heating [5]. Therefore,

43 analysis of biomass properties is essential to understand, predict, and control conversion systems.

$44 \mathrm{HHV}$ is an important thermal property to characterize how much energy can be produced by the

45 combustion of a unit of biomass. Elemental composition analysis, including carbon, oxygen,

46 hydrogen, nitrogen, and sulfur, is necessary to calculate biomass heat content, perform mass and

47 heat balances in the bioconversion process, and predict potential pollution complications during

48 biomass thermal processes. The high heating value (HHV) and elemental composition of

49 biomass feedstock determine the theoretical biomass conversion efficiency and have a great

50 impact on bio-industry economics. In order to effectively use different types of biomass and to

51 fast predict biomass energy potential, studies have explored correlations between HHV and

52 elemental composition of biomass [6-9], but determination of HHV and elemental composition is

53 limited by costly, labor-intensive conventional methods. HHV has been determined by absorbed

54 heat from completed combustion in an oxygen bomb calorimeter, a process that usually requires

55 at least 25 min per measurement, plus sample pelleting and replication. Elemental composition 
56 analysis is also time-consuming and expensive; therefore, rapid, inexpensive methods of 57 analyzing biomass properties must be developed.

58 NIR is a rapid measurement technique based on spectrum absorption by a specific function 59 group within a biomass. NIR has shown advantages in harsh industrial biomass utilization, such 60 as high-throughput, online, and non-destructive prediction $[10,11]$. Some studies have used NIR 61 to predict carbon, hydrogen, and nitrogen in coal [12, 13]. Alciaturi et al. [14] built an NIR 62 model of the heating value of coal with good correlations $(\mathrm{R}>0.9)$. NIR has also been used to 63 model carbon and nitrogen of soil and plant materials [15] and analyze HHV and elemental 64 composition of biomass. Lestander and Rhen [16] effectively modeled HHV of Norway spruce 65 with a coefficient of variation of $0.6 \%$. Allison et al. [17] studied the feasibility of using NIR to 66 predict nitrogen content of two dried grass species in different growing conditions with $R^{2}=0.94$.

67 HHV and carbon content of miscanthus and short-rotation coppice willow have been modeled by 68 NIR with $\mathrm{R}^{2}=0.99$ and 0.88 , respectively [18]. Follow-up research determined the accuracy of 69 visible and NIR models by PLS regression method with a root mean square error of cross70 validation (RMSECV) of $0.30 \mathrm{MJ} \mathrm{Kg}^{-1}$ and coefficient of determination $\left(\mathrm{R}^{2}\right)$ of 0.97 [19]. 71 Lestander et al. [20] reported NIR provided excellent prediction of HHV of bio-coal from 72 torrefaction and pyrolysis of biomass, and the optimal model can explain 96\% variance of HHV. 73 Via et al. [21] modeled HHV changes of sweetgum, loblolly, pine, and switchgrass after 74 torrefaction with NIR and Fourier Transform infrared spectroscopy (FTIR). The NIR model 75 developed by Gillespie et al. had high accuracy for prediction of HHV of wood, miscanthus and 76 herbaceous energy grasses with $\mathrm{R}^{2}=0.94$ [22]. Recently, the performance of HHV and 77 elemental composition prediction of 222 straw samples using NIR has been studied [6, 23]. Xiao 78 et al. [24] reviewed NIR coupled with multivariate data analysis as a high-throughput technique 
79 to evaluate $\mathrm{HHV}$ and other important properties. In our previous study, both structural

80 polysaccharides and soluble sugars were predicted using NIR with PLS method at reliable

81 predication with $\mathrm{R}^{2}$ of 0.87 and 0.90 for structural polysaccharides and soluble sugars,

82 respectively [25]. In addition, this study is part of a sorghum biomass genomics and phenomics

83 project to investigate the relationship between genotype and selectively phenotype in 100

84 sorghum accessions with maximum of genotyping diversity, allowing efficient and cost-effective

85 genome sequencing and breeding. NIR model development is high-throughput and cost-effective

86 method to link the observed phenotypic variation for biofuel conversion and genes and

87 germplasm variation.

88 Although NIR has been used extensively in the food, pharmaceutical, and agricultural fields

89 [26-28], to our knowledge, no published information exists on HHV and elemental composition

90 modeling of sorghum biomass using NIR. Unlike biomass yield, which can be easily measured

91 by a biomass harvester, measurement of HHV and elemental composition of biomass needs

92 advanced instruments and requires trained professional with high cost and labor intensive. With

93 NIR technology, chemical composition and physical properties of biomass can be rapidly and

94 accurately measured. The main advantages of NIR spectroscopy technology are that sample

95 preparation is simple, analysis is fast and precise, and many constituents can be analyzed at the

96 same time. Therefore, NIR technology can enable us to develop high-throughput phenotyping

97 methods and to allow us to obtain a broad view of genetic diversity in biomass germplasm. The

98 objective of this research was to develop standardized NIR models in conjunction with

99 chemometrics to high-throughput and cost-effective determine HHV and elemental composition

100 of sorghum biomass. This is the first report to model HHV and elemental composition of

101 sorghum biomass via NIR coupled with multivariate data analysis. The NIR method significantly 
102 reduced the time (from 100 to $1 \mathrm{~min}$ ) and cost (from 200 to 1 USD) of the determination of

103 biomass HHV and elemental composition. Last but not least, this study leverage a high-

104 throughput, cost-effective phenotype of HHV and elemental in sorghum biomass to facilitate

105 plant breeding and genetics studies. Future work of the NIR model should focus on developing a

106 model system to achieve rapid analysis of genomics at low cost to assist plant feedstock

107 improvement.

108 2. Materials and Methods

1092.1 Materials

110 Samples of the most representative 100 accessions of sorghum used in this study were

111 harvested in Lubbock, TX in October 2012. Samples were provided by the United States

112 Department of Agriculture National Plant Germplasm System (USDA-NPGS), in which 44,774

113 accessions of sorghum originated from 116 countries. After harvest, biomass samples were air-

114 dried at $60{ }^{\circ} \mathrm{C}$ and ground to particle size of $0.5 \mathrm{~mm}$ (UDY cyclone mill, Fort Collins, CO) for

$115 \mathrm{HHV}$ and elemental analysis. After grinding, all samples were stored in sealed plastic bags. All

116 measurements were carried out in a short time at a lab with stable environmental conditions of 22

$117{ }^{\circ} \mathrm{C}$ and $40 \%$ humidity. All chemicals were purchased from Sigma (St. Louis, MO).

$118 \quad 2.2$ Reference methods

119 HHV was determined using a calorimeter (IKA-Calorimeter C 200, IKA-Werke GmbH and

120 Co. KG, Staufen, Germany) with a benzoic acid standard. Approximately $1.00 \mathrm{~g}$ of each pelleted

121 sample was put into an adiabatic bomb calorimeter and burned to ash. Powder samples were

122 compacted into pellets for measurement in order to reduce error caused by incomplete

123 combustion resulting from dry, loose samples blown away during sudden release of volatiles. 
124 The elemental composition of sorghum biomass samples was measured with CHNS/O 125 Elemental Analyzer (PerkinElmer 2400 Series II, PerkinElmer Inc., Waltham, MA). Two to 126 three milligrams (accurate to $0.001 \mathrm{mg}$ ) of the ground sample with fine uniform particle size was 127 weighted into tin capsules using a PerkinElmer AD-6 Autobalance (PerkinElmer Inc., Waltham, 128 MA). The ground sample was packed with foil, introduced into the combustion chamber through 129 a funnel, and burned under a pure oxygen atmosphere. Gases from combustion $\left(\mathrm{CO}_{2}, \mathrm{~N}_{2}, \mathrm{SO}_{2}\right.$, 130 and $\mathrm{H}_{2} \mathrm{O}$ ) were separated in a quartz column containing copper wires detected by a 131 thermoconductometer detector. Elemental compositions were reported as a percentage of initial 132 dry weight $(w / w, d b)$.

\section{$133 \quad 2.3$ Multiple linear regression analysis}

134 Multiple linear regression (MLR) analysis was carried out to estimate the relationship between 135 HHV and elemental compositions. Pearson correlations between two parameters and multiple 136 stepwise regression of all parameters were analyzed using SAS (SAS Institute, Inc., Cary, NC). 137 All significance analysis was at significance level 0.05 .

\subsection{NIR measurement}

139 NIR spectra were measured with an Antaris II FT-NIR analyzer (Thermo Scientific Inc.,

140 Madison, WI, USA) in reflectance mode. A sample cup spinner (Thermo Scientific, WI, USA)

141 with an Integrating Sphere module was used to quickly and reliably obtain bulk information from

142 powder biomass. Spectra were collected by rotating the sample cup through the NIR beam. Each 143 spectrum was averaged with 32 scans at a resolution of $4 \mathrm{~cm}^{-1}$ in the wavelength range of 4,000$14410,000 \mathrm{~cm}^{-1}$. 
146 Spectra pretreatment and chemometric analysis was conducted by TQ Analyst 8.6.12 (Thermo

147 Scientific Inc., Madison, WI). Pathlength was calibrated using standard normal variate (SNV)

148 and multiplicative signal correction (MSC). The Savitzky-Golay filter was used to reduce

149 random noise. First and second derivatives were used as a pretreatment method to resolve spectra

150 peak overlap and eliminate linear baseline drift. The first derivative was the rate of change of

151 absorbance with respect to wavelength, whereas the second derivative corresponded to the

152 curvature or concavity of the graph. First and second spectra formats were compared.

153 To avoid bias in the subset and achieve a calibration set and validation set with a ratio of 3 , the

154 entire set of 100 sorghum biomass samples was sorted ascendingly by measured value. One in

155 every four samples was randomly assigned to the prediction set (25), with remaining samples as

156 calibration samples (75). A full spectra range from 4,000 to $10,000 \mathrm{~cm}^{-1}$ was used unless

157 otherwise specified. PLS and PCR methods described in the literature [11] were used for model

158 development. Model performance was evaluated in terms of the coefficient of determination $\left(\mathrm{R}^{2}\right)$,

159 root mean square error of calibration (RMSEC), root mean square error of prediction (RMSEP),

160 and ratio of standard deviation of calculated set $\left(\mathrm{SD}_{\mathrm{y}}\right)$ to $\mathrm{RMSEP}(\mathrm{RPD})$, calculated with the

161 equations:

$$
\begin{gathered}
R M S E C=\sqrt{\frac{\sum_{i=1}^{n_{c}}\left(\hat{\mathrm{y}}_{i}-y_{i}\right)^{2}}{n_{c}}}(1) \\
R M S E P=\sqrt{\frac{\sum_{i=1}^{n_{p}}\left(\hat{\mathrm{y}}_{i}-y_{i}\right)^{2}}{n_{p}}}(2) \\
R P D=\frac{S D_{y}}{R M S E P}(3)
\end{gathered}
$$


162 where $n_{c}$ and $\mathrm{n}_{\mathrm{p}}$ are the number of samples in calibration set and prediction set, respectively, $\hat{y}_{i}$

163 and $y_{i}$ are the predicted value and measured value of the $i^{\text {th }}$ sample, respectively, and $S D_{\mathrm{y}}$ is

164 standard deviation of calculated set.

165 The Chauvenet test was used to eliminate outliers defined as the points at distances in the

166 principle component space greater than 3.0. Predicted residual error sum of squares (PRESS)

167 diagnostic function was used to determine the number of factors necessary for calibration.

\section{3. Results and Discussion}

\subsection{Samples statistics}

170 Table 1 summarizes the range, mean, and standard deviation of $\mathrm{HHV}$ and elemental

171 composition of sorghum biomass samples using reference methods. The representative 100

172 accessions of sorghum biomass samples showed good range and distribution: 15.67 to 16.99

$173 \mathrm{MJ} / \mathrm{kg}$ with standard deviations of $0.26 \mathrm{MJ} / \mathrm{kg}$ for $\mathrm{HHV}, 39.65$ to $42.37 \%$ with standard

174 deviation $0.57 \%$ for carbon content, 4.26 to $6.4 \%$ with standard deviation $0.43 \%$ for hydrogen

175 content, 0.47 to $1.65 \%$ with standard deviation $0.22 \%$ for nitrogen content, 0.24 to $1.5 \%$ with

176 standard deviation $0.17 \%$ for sulfur content, and 50.13 to $53.24 \%$ with standard deviation $0.59 \%$

177 for oxygen content. In addition, the range, mean, and standard deviation of the calibration set

178 covered the validation set, and both subsets showed consistent distribution for robust model

179 construction. The range of HHV and elemental composition were similar to those reported by

180 previous research [29, 30]. In generally, biomass has similar HHV ranged from 12 to $18 \mathrm{MJ} / \mathrm{kg}$,

181 whereas coal has higher HHV of 26-30 MJ/kg [31].

182 The Pearson correlation coefficient was employed to analyze relationships between variables.

183 As shown in Table 2, a strong correlation was observed between HHV and carbon $(\mathrm{R}=0.841, p$ 
$184<0.01)$, HHV and oxygen $(\mathrm{R}=-0.692, p<0.01)$, and carbon and oxygen $(\mathrm{R}=-0.822, \mathrm{p}<0.01)$.

185 This result suggests that sorghum biomass with higher carbon content and lower oxygen content

186 could release additional heat after combustion. Nitrogen element in sample was converted to

187 simple gas $\mathrm{N}_{2}$ in combustion process and showed a negative correlation between it and HHV, 188 possibly as a result of relationships between elements such as carbon and nitrogen $(\mathrm{R}=-0.527)$.

189 A MLR model was developed; regression coefficient results of the model are listed in Table 3. 190 Although only one model was obtained from MLR, this model showed good performance, with a 191 high $\mathrm{R}^{2}=0.84$ and low p-value $<0.001$ with $F$ value of 237.18 , as shown below:

$$
\text { High heating value }=1.325+0.841 \times \text { Carbon }
$$

192 In this equation, hydrogen, nitrogen, sulfur, and oxygen were not significantly independent, even 193 though HHV showed significant correlations with nitrogen and oxygen. A possible reason is that 194 there were strong collinearity between carbon, nitrogen and oxygen. MLR with stepwise 195 exclusively selected optimal variables rather than all significant variables in Pearson correlation. 196 As carbon content of sorghum biomass sample increased by $1 \%$, HHV of the sample increased $1970.841 \mathrm{KJ}$, significantly differing from a majority of previous results $[6,8,32]$. This result could 198 have been caused by strong multicollinearity between independent variables [33]; however, 199 Tillman [34] proposed a classic equation in which only carbon content was correlated with HHV. 200 From MLR regression results, prediction of HHV from elemental composition is a fairly reliable 201 method $\left(\mathrm{R}^{2}=0.84\right)$, a less expensive, more accurate method to measure HHV and elemental 202 composition must be found.

\subsection{Samples spectra}


204 The near-infrared spectrum of 100 sorghum biomass samples in the $4000-10000 \mathrm{~cm}^{-1}$ range is 205 presented in Fig. 1. In general, all NIR spectra exhibited three main peaks. The first peak was 206 relatively wide, between 6550 and $7100 \mathrm{~cm}^{-1}$, in relation to cellulose $\left(6711 \mathrm{~cm}^{-1}\right)$ and $\mathrm{O}-\mathrm{H}$ 207 stretch in the first overtone of $\mathrm{H}_{2} \mathrm{O}\left(6897 \mathrm{~cm}^{-1}\right)$ and the $\mathrm{C}-\mathrm{H}$ combination of aromatic structures 208 from lignin $\left(6915 \mathrm{~cm}^{-1}\right)$ [35]. The second peak at $5180 \mathrm{~cm}-1$ was associated with $\mathrm{O}-\mathrm{H}$ 209 stretch/HOH deformation from a combination of cellulose [35]. The third peak could correspond 210 [36] to the asymmetrical C-O-O stretch in the third overtone of cellulose $\left(4745 \mathrm{~cm}^{-1}\right)$ [35].

\subsection{NIR model development for HHV}

212 Calibration models for predicting HHV were developed using PCR and PLS methods. Table 4

213 shows that PLS always had better performance than PCR based on larger $\mathrm{R}^{2}$ and RPD, thereby 214 indicating that PLS is a more powerful quantitative analysis for HHV of sorghum biomass. For

215 PLS analysis methods, all relevant spectral information in the analysis region or regions of the 216 calibration spectra were condensed into a set of principal components. Each principal component 217 (PC) represented an independent source of spectral variation in the data. PC analysis plots were 218 helpful in examining sample groups on the basis of similar characteristics and in identifying 219 outliers. Fig. 2A shows plots of PC analysis scores of HHV. PC1 described a majority of 220 variation in the calibration spectra and accounted for $86.78 \%$ of variation explanation; PC2 221 represented $8.99 \%$ of variation among the samples. Distribution of sample dots was wide and 222 symmetrical, suggesting that the samples were representative and there were no obvious outliers.

223 Spectra processes such as derivatives were applied to improve model prediction. The 224 performance of models after first and second derivatives treatment is summarized in Table 4. 225 Neither first nor second derivative treatment significantly increased goodness-of-fit of calibration 
226 and validation sets, suggesting derivative spectra were not useful for HHV model development 227 because spectra transformation generated false information from mathematical artifacts [37]. To 228 further optimize the HHV model, a reduced spectral range was used to decrease noise. In Fig. 3 229 A, the mean spectra (red curve) show the average of all spectra. The variance spectra (blue 230 curve), which show variance in all spectra, was produced by calculating the square root of the 231 spectral variance at each HHV value across all spectra. The regression coefficient spectra (black 232 curve) indicate which wavelengths had larger weights in the calibration model. Wavelengths 233 from 6000 to $7000 \mathrm{~cm}^{-1}$ were selected as reduced wavelength regions to improve the model 234 because of their high coefficient and high variance, thereby indicating high correlation and larger 235 variation. The reduced-wavelength region had better model performance than the full-range 236 model, with $\mathrm{R}^{2}$ of 0.96 , RMSEP of $0.061 \mathrm{KJ} / \mathrm{Kg}$, and RPD of 4.59 for the validation sample set, 237 indicating that this model is able to provide an accurate prediction and could be used in most 238 applications [38]. This result is in good agreement with a previous study in which wavelengths 239 from 6500 to $8500 \mathrm{~cm}^{-1}$ were considered the important region in order to predict HHV because 240 this region was assigned to the $\mathrm{C}-\mathrm{H}$ stretching (second overtone) of aromatic and $\mathrm{CH}_{3}$ structures 241 [18]. Lestander et al. [10] reported that HHV prediction using peaks of NIR spectra at 6900 and $2425200 \mathrm{~cm}^{-1}$, which associated with $\mathrm{O}-\mathrm{H}$ stretching and bending in water. Moreover, Lestander and 243 Rhen [16] listed covalent bonds contributing to HHV in decreasing order, $\mathrm{C}=\mathrm{C}, \mathrm{S}-\mathrm{H}, \mathrm{C}-\mathrm{H}, \mathrm{C}-\mathrm{C}$, $244 \mathrm{C}-\mathrm{N}, \mathrm{N}-\mathrm{H}, \mathrm{C}=\mathrm{O}, \mathrm{C}-\mathrm{O}$, and $\mathrm{O}-\mathrm{H}$. All 10 calculated factors were used in calibration models, 245 suggesting that calculated factors were insufficient. Fig. 4A shows the plot of calculated versus 246 actual HHV in the improved model. The model was robust and excellent for predicting HHV of 247 sorghum biomass samples. The optimal model for HHV prediction this study yielded better 248 performance than existing NIR model for coal [14], Norway spruce [16], and short-rotation 
249 coppice willow, whereas slightly worse than HHV prediction model for miscanthus with $\mathrm{R}^{2}=$ $250 \quad 0.99$.

\subsection{NIR model development for carbon content}

252

253

254

255

Table 5 shows models' performances related to carbon content prediction. Full-range spectra were used in PLS and PCR models to yield similar $\mathrm{R}^{2}$ of 0.88 in the validation set. However, the PLS model had better fitness in the calibration set, with $\mathrm{R}^{2}$ of 0.88 and RPD of 3.03, compared to the PCR model, with $\mathrm{R}^{2}$ of 0.71 and RPD of 2.60 (Table 5). In Fig. 2B, PC1 and PC2 explain $73.52 \%$ and $23.81 \%$ of variance in the samples' carbon contents. Distribution of sample dots was not as good as in the HHV model, resulting in lower fitness. The first derivative of spectra slightly increased model performance, with $\mathrm{R}^{2}$ of 0.9 in the calibration set and RPD of 3.39, but the second derivative of spectra did not improve the model. According to the same principle of reduced range as in the HHV model, wavelengths from 4362 to $7000 \mathrm{~cm}^{-1}$ in Fig. 3B were optimal for the carbon content prediction model. This range was essential for predicting carbon content because it contained $\mathrm{C}-\mathrm{H}$ stretching and/or deformation of $\mathrm{CH}, \mathrm{CH}_{2}, \mathrm{CH}_{3}$, aromatics, CHO and cellulose $\left(7000,5900,5800,4550\right.$, and $\left.4350 \mathrm{~cm}^{-1}\right)$; O-H stretching and deformation of $\mathrm{ROH}$ at 7010 and $4800 \mathrm{~cm}^{-1}$, respectively; $\mathrm{C}=\mathrm{O}$ stretching (second overtone) of $-\mathrm{CO}_{2} \mathrm{H}, \mathrm{CONH}$, and $\mathrm{CONH}\left(5260,5200\right.$, and $\left.4920 \mathrm{~cm}^{-1}\right)$; N-H stretching (first overtone) of $\mathrm{CONH}_{2}\left(6990 \mathrm{~cm}^{-1}\right)$; and S-H stretching (first overtone) of $-\mathrm{SH}\left(5740 \mathrm{~cm}^{-1}\right)$ [18]. Reduced range significantly increased calibration $\mathrm{R}^{2}$ in raw spectra, first derivative spectra, and second derivative spectra, but reduced range worsened performance in validation $R^{2}$ in first derivative spectra and second derivative spectra. The best carbon prediction model using PLS with raw spectra in 4362 to 7000 $\mathrm{cm}^{-1}$ had a validation $\mathrm{R}^{2}$ of 0.96 , RMSEP of $0.115 \%$, and RPD of 4.69. For optimal prediction, factor number adjustment was based on the PRESS plot of various calculated factor numbers, in 
272 which PRESS value was inversely proportional to prediction performance. The factor number of

2738 in the current model was less than that of calculated factor number (10), suggesting no

274 additional factor numbers were needed for calibration. As shown in Fig. 5, PRESS values in the

275 plot reached the turning point at six factors, gradually decreased, and finally leveled off to a

276 constant value. Although PRESS values eventually decreased below the turning point when more

277 factors were used, model performance was not likely to improve, possibly decreasing if the

278 calibration model became overfit. Fig. 4B compares calculated versus actual carbon content in

279 order to demonstrate excellent prediction of the model for potential use in most applications.

280 This NIR model showed comparable performance as previous researches, such as carbon

281 prediction model for coal [12], heterogeneous plant material [15], as well as switch grass and

282 reed canary grass [17].

284 Prediction models for hydrogen, nitrogen, sulfur, and oxygen contents were developed by 285 strategies similar to those outlined above, as summarized in Table 6. PLS analysis was applied in 286 selection of all quantitative methods. All elemental composition had SNV pathlength data 287 processing, with the exception of MSC for hydrogen for which the best model had $\mathrm{R}^{2}$ of 0.93 for 288 the calibration sample set, $\mathrm{R}^{2}$ of 0.87 for the validation sample set, and RMSEP of $0.072 \%$ and 289 RPD 2.52 with no spectral treatment in the spectral region $4500-9800 \mathrm{~cm}^{-1}$. Prediction nitrogen 290 model was developed with SNV treatment and no spectral treatment in the spectral region 5000$2915500 \mathrm{~cm}^{-1}$ to achieve good fitness as $\mathrm{R}^{2}$ of 0.86 for the prediction sample set. Sulfur models had 292 best performance with $\mathrm{R}^{2}$ of 0.88 for the calibration sample set and $\mathrm{R}^{2}$ of 0.84 for the prediction 293 sample set in the full wavelength range, which is less robust. One possible reason for the fair 294 performance of nitrogen and sulfur models is the low concentration with relatively higher 
295 variation in samples. Oxygen prediction was fair after treating spectra with the first derivative

296 and reducing the range from $4500-8000 \mathrm{~cm}^{-1}$; the model had a calibration $\mathrm{R}^{2}$ of 0.83 , a validation

$297 \mathrm{R}^{2}$ of 0.83 , an RMSEP of $0.166 \%$, and an RPD of 3.37. The decreased fitness of the oxygen

298 prediction model was likely caused by the non-independence of oxygen, calculated from the

299 difference between $100 \%$ and the sum of carbon, hydrogen, nitrogen, and sulfur. This result also

300 confirmed the strong multicollinearity of MLRs. Although prediction models of hydrogen,

301 nitrogen, sulfur, and oxygen were not as good as HHV and carbon content prediction models,

302 they are still good enough to use with caution in most applications, such as research studies and

303 screenings [38].

304 4. Conclusion

305 Models to predict HHV, carbon, hydrogen, nitrogen, sulfur, and oxygen contents of sorghum

306 biomass were well developed. HHV, carbon, hydrogen, nitrogen, sulfur, and oxygen contents

307 were predicted with validation $\mathrm{R}^{2}$ of $0.96,0.96,0.87,0.86,0.84$, and 0.83 , respectively. HHV

308 and carbon content were deemed excellent and suitable for use in any application. The hydrogen,

309 nitrogen, sulfur and oxygen models could be usable with caution in most application such as

310 research study. The NIR method significantly reduced the time (from 100 to $1 \mathrm{~min}$ ) and cost

311 (from 200 to 1 USD) of the determination of biomass HHV and elemental composition. The

312 future work of the NIR model should focus on developing a model system to achieve rapid

313 analysis of genomics at low cost to assist plant feedstock improvement. This study would be very

314 useful for scientists in research institutions, engineers in bio-industries, and biomass producers,

315 and also filling the gap between plant breeding and various biomass applications.

\section{Acknowledgment}


317 This work was supported by Agriculture and Food Research Initiative Competitive Grant 201131803587 from the US Department of Agriculture National Institute of Food and Agriculture. We

319 thank Mrs. Kristen Hale for NIR measurement. Chromatin Inc. provided the sorghum biomass 320 samples for this research.

\section{$321 \quad$ Nomenclature}

\begin{tabular}{|ll|}
\hline FTIR & fourier Transform infrared spectroscopy \\
HHV & high heating value \\
MSC & multiple linear regression \\
NIR & multiplicative signal correction \\
PCR & near-infrared spectroscopy \\
PLS & principle component regression \\
PRESS & partial least squares \\
RMSEC & Predicted residual error sum of squares \\
RMSECV & root mean square error of calibration \\
RMSEP & root mean square error of cross-validation \\
RPD & root mean square error of prediction \\
SD & ratio of standard deviation of calculated set \\
SNV & standard deviation of calculated set \\
\hline
\end{tabular}

\section{References}

325 [1] Kim TH, Kim TH. Overview of technical barriers and implementation of cellulosic ethanol in 326 the US. Energy. 2014;66:13-9.

327 [2] Zhan X, Wang D, Bean S, Mo X, Sun X, Boyle D. Ethanol production from supercritical328 fluid-extrusion cooked sorghum. Industrial Crops and Products. 2006;23(3):304-10. 
[3] Sasaki T, Antonio BA. Plant genomics: Sorghum in sequence. Nature. 2009;457(7229):547-8.

330 [4] Hames BR, Thomas SR, Sluiter AD, Roth CJ, Templeton DW. Rapid biomass analysis. 331 Biotechnology for Fuels and Chemicals. New York, USA: Springer; 2003. p. 5-16.

332 [5] Esen M, Yuksel T. Experimental evaluation of using various renewable energy sources for 333 heating a greenhouse. Energy and Buildings. 2013;65:340-51.

334 [6] Huang C, Han L, Yang Z, Liu X. Ultimate analysis and heating value prediction of straw by near infrared spectroscopy. Waste Management. 2009;29(6):1793-7.

[7] Zhang K, Johnson L, Nelson R, Yuan W, Pei Z, Sun XS, et al. Thermal properties of big bluestem as affected by ecotype and planting location along the precipitation gradient of the Great Plains. Energy. 2014;64:164-71.

[8] Demirbas A. Calculation of higher heating values of biomass fuels. Fuel. 1997;76(5):431-4.

[9] Sheng C, Azevedo J. Estimating the higher heating value of biomass fuels from basic analysis data. Biomass and Bioenergy. 2005;28(5):499-507.

[10] Lestander TA, Johnsson B, Grothage M. NIR techniques create added values for the pellet and biofuel industry. Bioresource technology. 2009;100(4):1589-94.

[11] Xu F, Yu J, Tesso T, Dowell F, Wang D. Qualitative and quantitative analysis of lignocellulosic biomass using infrared techniques: A mini-review. Applied Energy. 2013;104:801-9.

[12] Kaihara M, Takahashi T, Akazawa T, Sato T, Takahashi S. Application of near infrared spectroscopy to rapid analysis of coals. Spectroscopy letters. 2002;35(3):369-76.

[13] Andres J, Bona M. Analysis of coal by diffuse reflectance near-infrared spectroscopy. Analytica chimica acta. 2005;535(1):123-32.

[14] Alciaturi CE, Escobar ME, Vallejo R. Prediction of coal properties by derivative DRIFT spectroscopy. Fuel. 1996;75(4):491-9.

[15] Gillon D, Houssard C, Joffre R. Using near-infrared reflectance spectroscopy to predict carbon, nitrogen and phosphorus content in heterogeneous plant material. Oecologia. 1999;118(2):173-82.

[16] Lestander TA, Rhén C. Multivariate NIR spectroscopy models for moisture, ash and calorific content in biofuels using bi-orthogonal partial least squares regression. Analyst. 2005;130(8):1182-9.

[17] Allison GG, Morris C, Hodgson E, Jones J, Kubacki M, Barraclough T, et al. Measurement of key compositional parameters in two species of energy grass by Fourier transform infrared spectroscopy. Bioresource technology. 2009;100(24):6428-33.

[18] Fagan CC, Everard CD, McDonnell K. Prediction of moisture, calorific value, ash and carbon content of two dedicated bioenergy crops using near-infrared spectroscopy. Bioresource technology. 2011;102(8):5200-6.

[19] Everard CD, McDonnell KP, Fagan CC. Prediction of biomass gross calorific values using visible and near infrared spectroscopy. Biomass and Bioenergy. 2012;45:203-11.

[20] Lestander TA, Rudolfsson M, Pommer L, Nordin A. NIR provides excellent predictions of properties of biocoal from torrefaction and pyrolysis of biomass. Green Chemistry. 2014;16(12):4906-13.

[21] Via BK, Adhikari S, Taylor S. Modeling for proximate analysis and heating value of torrefied biomass with vibration spectroscopy. Bioresource technology. 2013;133:1-8.

[22] Gillespie GD, Everard CD, McDonnell KP. Prediction of biomass pellet quality indices using near infrared spectroscopy. Energy. 2015;80:582-8. 
[23] Huang C, Han L, Yang Z, Liu X. Prediction of heating value of straw by proximate data, and near infrared spectroscopy. Energy Conversion and Management. 2008;49(12):3433-8. [24] Xiao L, Wei H, Himmel ME, Jameel H, Kelley SS. NIR and Py-mbms coupled with multivariate data analysis as a high-throughput biomass characterization technique: a review. Frontiers in plant science. 2014;5. polysaccharides and soluble sugars in sorghum biomass using near-infrared spectroscopy. BioEnergy Research. 2015;8(1):130-6.

382 [26] Benito J, Ojeda B, Rojas S. Process analytical chemistry: Applications of near infrared 383 spectrometry in environmental and food analysis: An overview. Applied Spectroscopy Reviews. 384 2008;43(5):452-84.

385 [27] Stark E, Luchter K, Margoshes M. Near-infrared analysis (NIRA): A technology for quantitative and qualitative analysis. Applied Spectroscopy Reviews. 1986;22(4):335-99. [28] Cen H, He Y. Theory and application of near infrared reflectance spectroscopy in determination of food quality. Trends in Food Science \& Technology. 2007;18(2):72-83. [29] Lafitte H, Loomis R. Calculation of growth yield, growth respiration and heat content of grain sorghum from elemental and proximal analyses. Annals of botany. 1988;62(4):353-61. [30] Jenkins B, Baxter L, Miles Jr T, Miles T. Combustion properties of biomass. Fuel processing technology. 1998;54(1):17-46.

[31] Nunes L, Matias J, Catalão J. Mixed biomass pellets for thermal energy production: A review of combustion models. Applied Energy. 2014;127:135-40.

395 [32] Kieseler S, Neubauer Y, Zobel N. Ultimate and proximate correlations for estimating the higher heating value of hydrothermal solids. Energy \& Fuels. 2013;27(2):908-18.

399 [34] Tillman D. Wood as an energy resource. 1978.

400 [35] Burns DA, Ciurczak EW. Handbook of near-infrared analysis: CRC press, 2007.

401 [36] Adler PR, Grosso SJD, Parton WJ. Life-cycle assessment of net greenhouse-gas flux for bioenergy cropping systems. Ecological Applications. 2007;17(3):675-91. products. Practical Spectroscopy Series. 2001;27:419-74. 


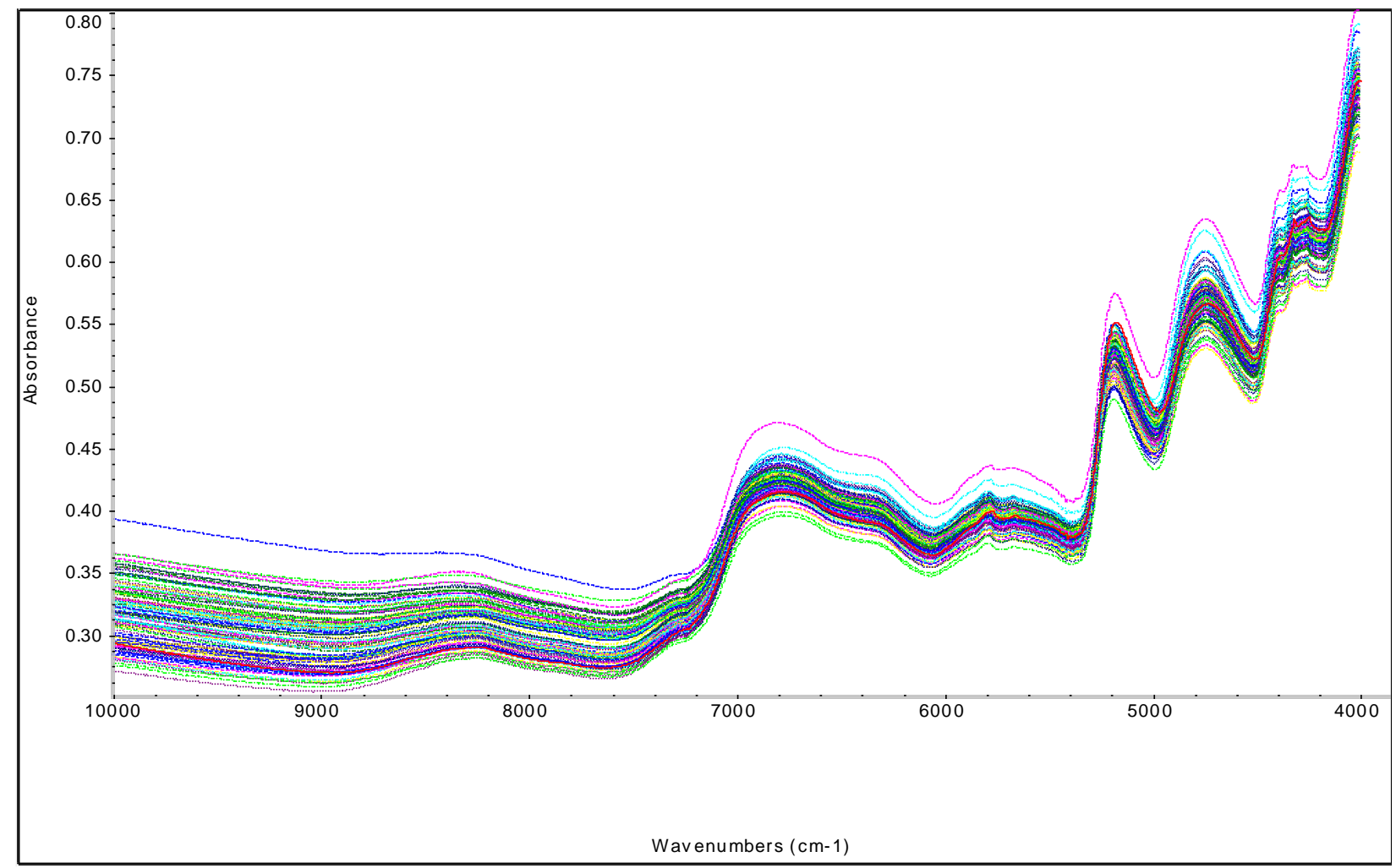

Fig. 1. Near-infrared spectra of one hundred sorghum biomass samples. 
A

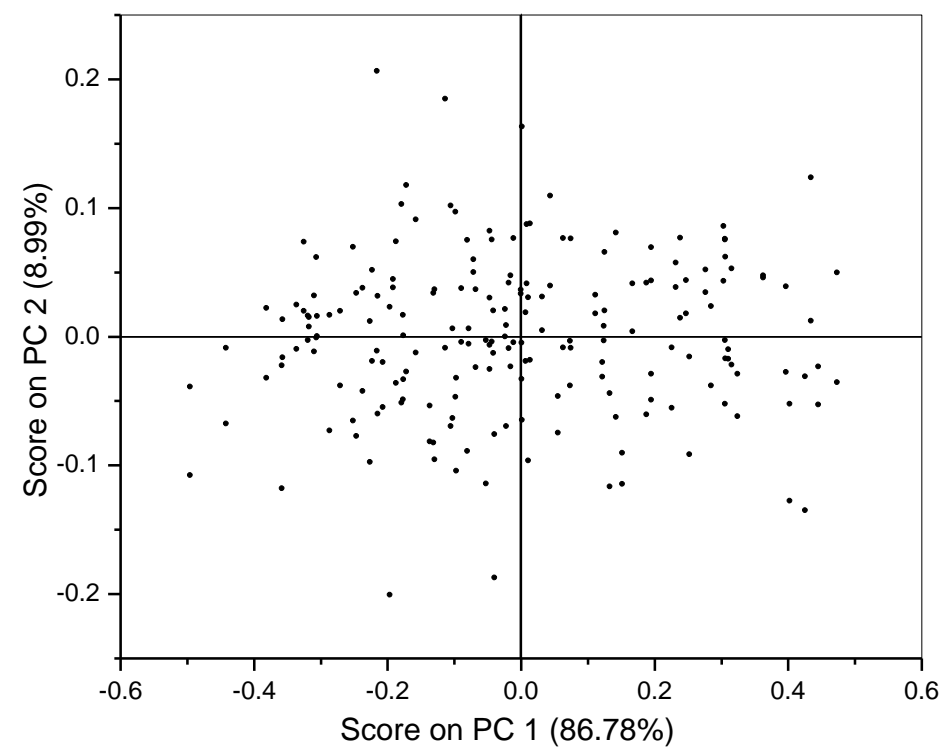

B

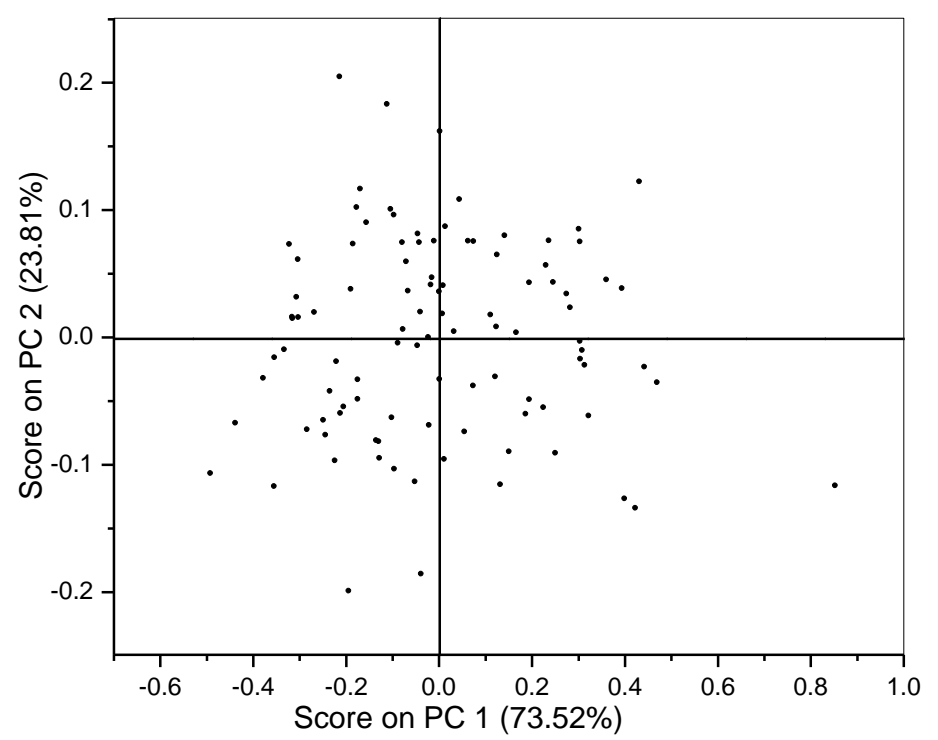

Fig. 2. Plot of principal component analysis scores of HHV (A) and carbon content (B) in PLS model. 
A

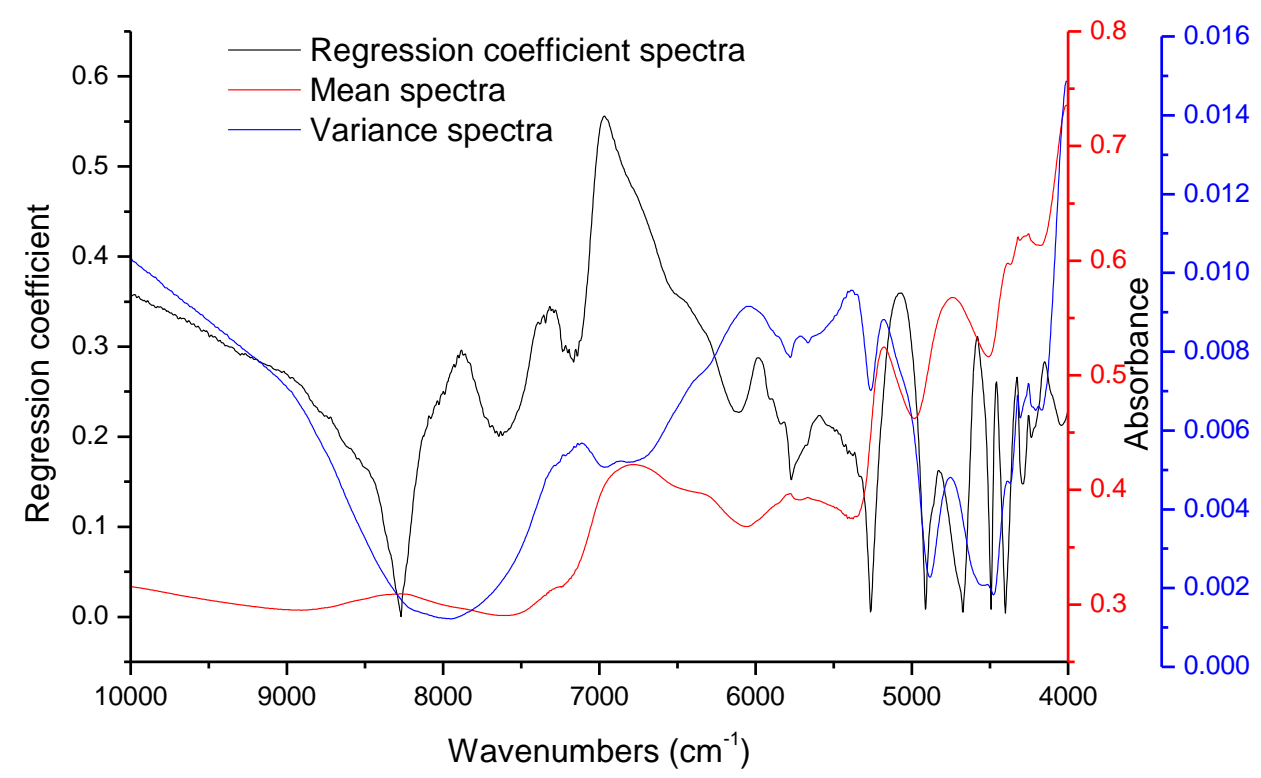

B

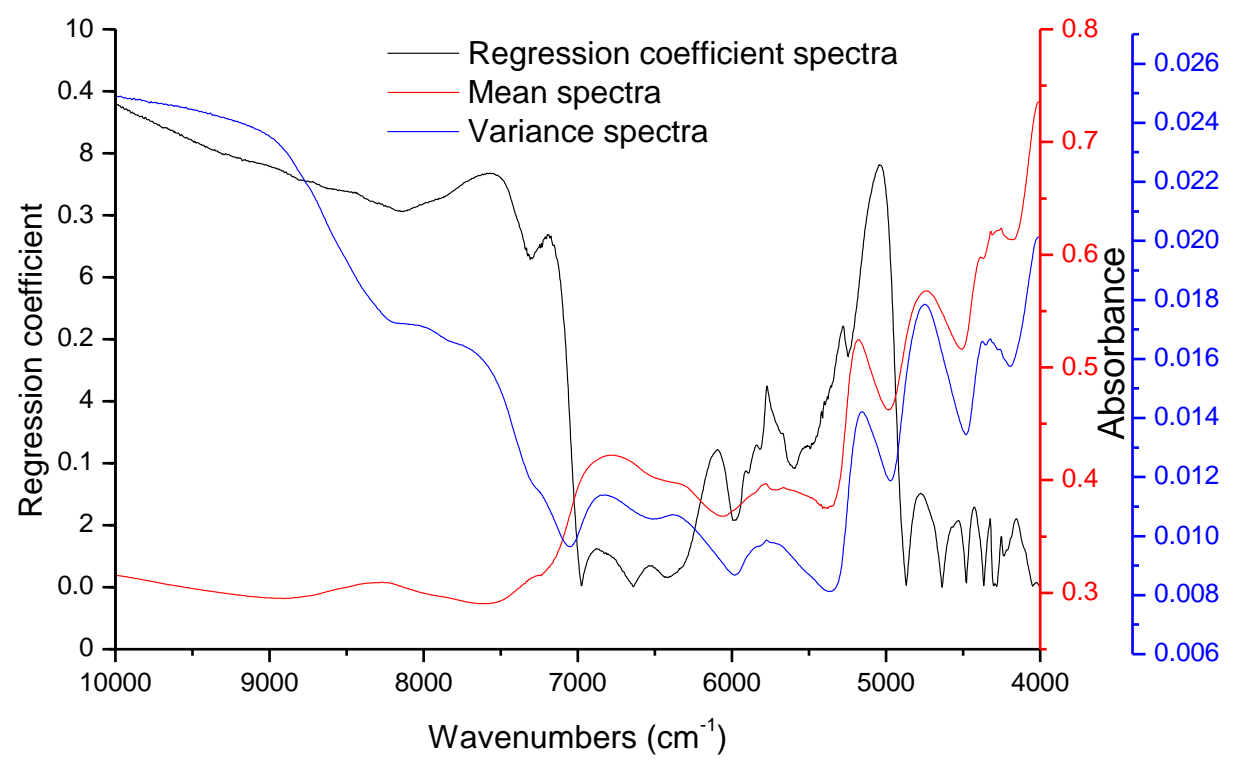

Fig. 3. Regression coefficient, mean, and variance spectra of HHV (A) and carbon content (B) in PLS model. 
A

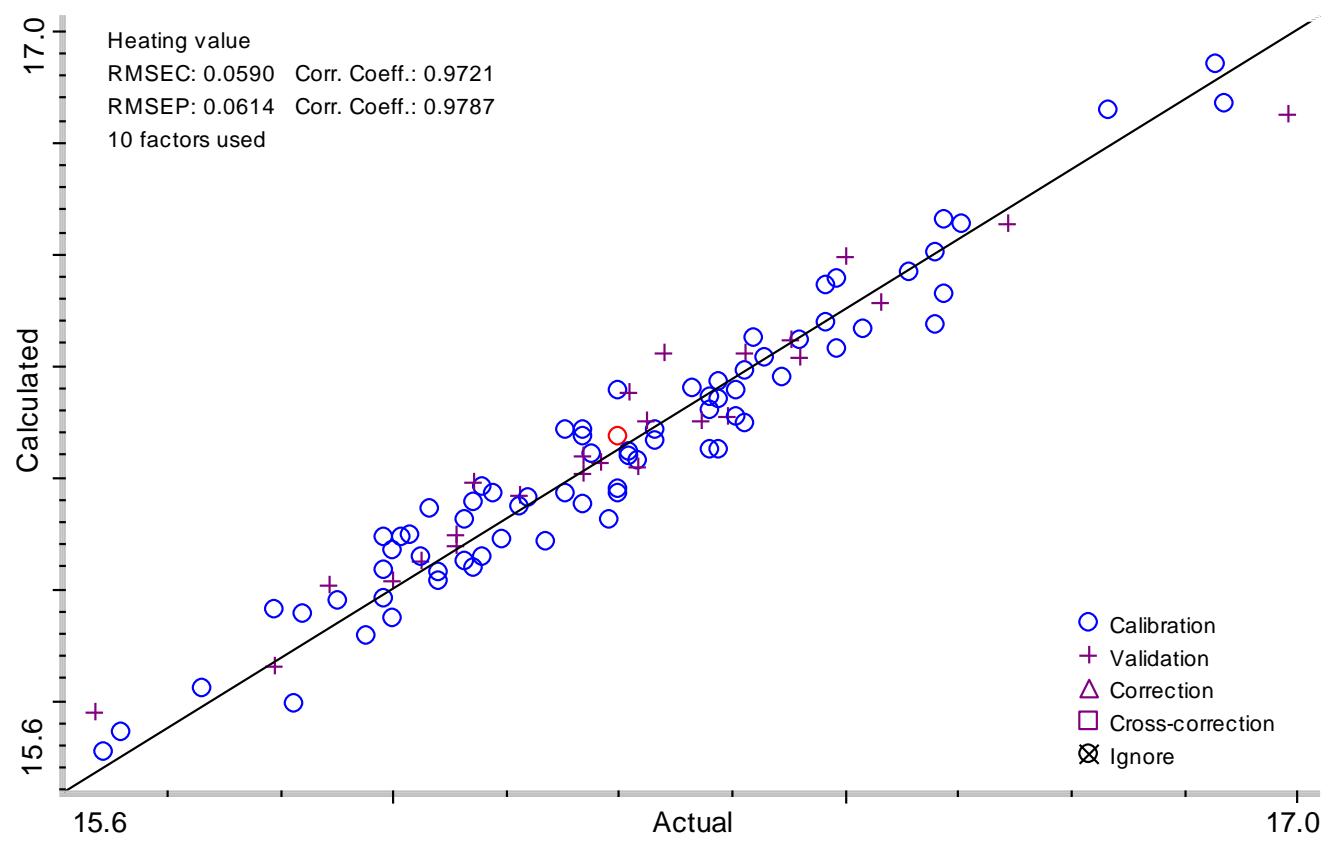

B

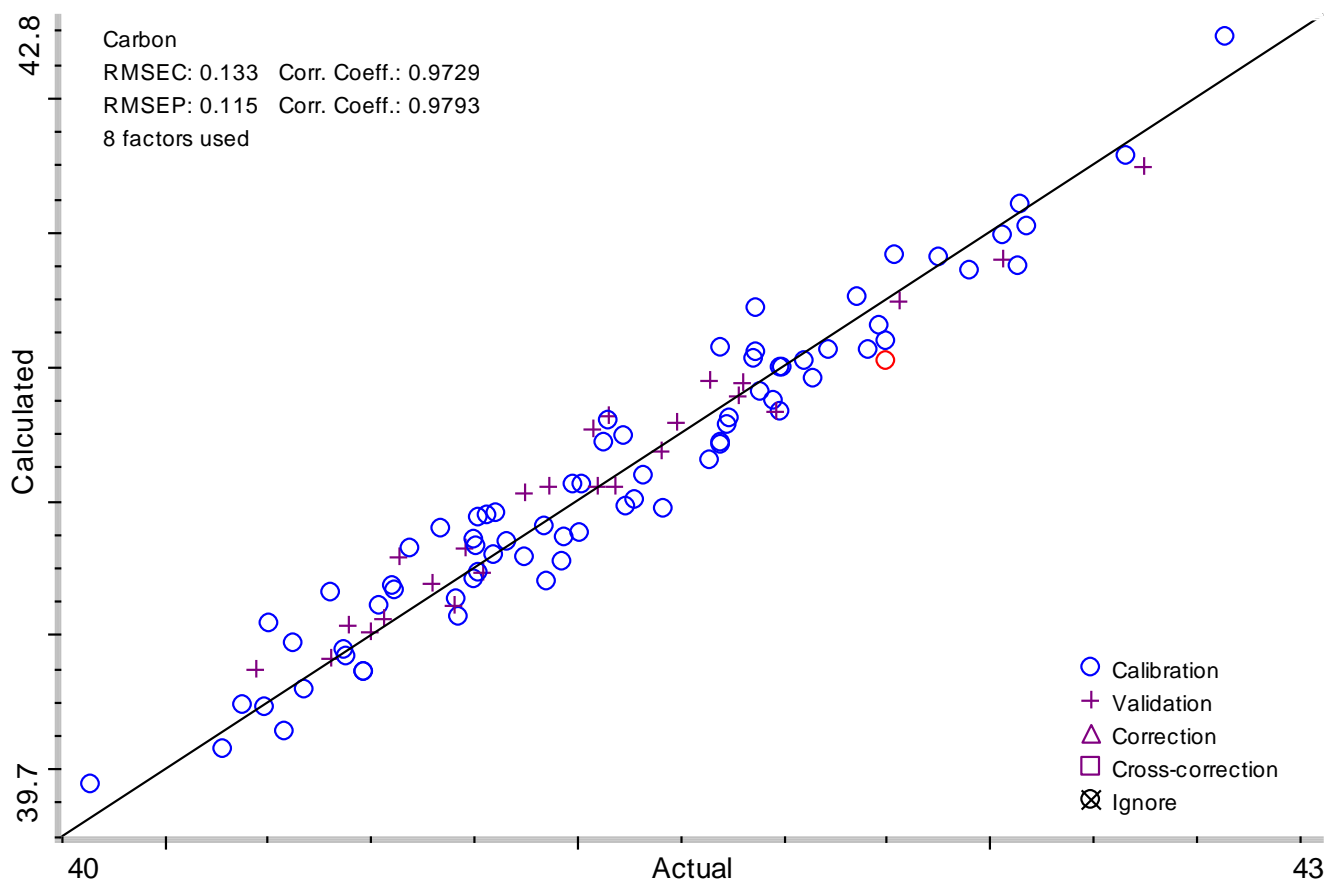

Fig. 4. Linear regression plots of calculated versus actual HHV (A) and carbon content (B). 


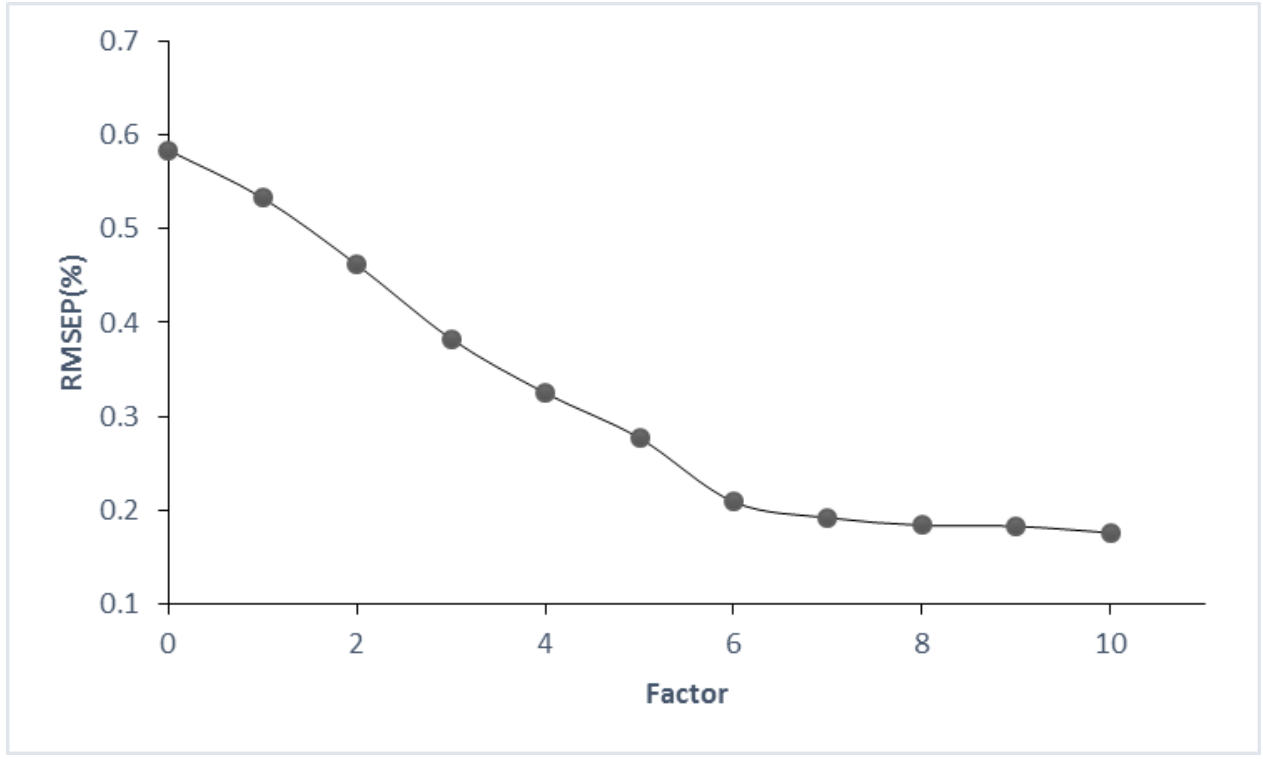

Fig. 5. Plot of PRESS of calculated factor numbers in carbon content prediction model. 
Table 1. Statistics of HHV and elemental composition of sorghum biomass using reference methods

\begin{tabular}{lccccccccc}
\hline & \multicolumn{3}{c}{ Full set } & \multicolumn{4}{c}{ Calibration set } & \multicolumn{3}{c}{ Validation set } \\
\cline { 2 - 10 } & Range & Mean & SD & Range & Mean & SD & Range & Mean & SD \\
\hline HHV (MJ/kg) & $15.67-16.99$ & 16.25 & 0.26 & $15.68-16.92$ & 16.24 & 0.28 & $15.67-16.99$ & 16.25 & 0.27 \\
Carbon (\%) & $39.65-42.37$ & 41.07 & 0.57 & $39.65-42.35$ & 41.09 & 0.59 & $40.22-42.37$ & 41.02 & 0.54 \\
Hydrogen (\%) & $4.26-6.4$ & 5.13 & 0.43 & $4.26-6.4$ & 5.12 & 0.49 & $4.88-5.49$ & 5.15 & 0.18 \\
Nitrogen (\%) & $0.47-1.65$ & 1.01 & 0.22 & $0.48-1.48$ & 1.00 & 0.21 & $0.47-1.65$ & 1.02 & 0.25 \\
Sulfur (\%) & $0.24-1.5$ & 1.19 & 0.17 & $0.24-1.50$ & 1.19 & 0.18 & $0.8-1.39$ & 1.19 & 0.15 \\
Oxygen (\%) & $50.13-53.24$ & 51.61 & 0.59 & $50.13-53.24$ & 51.63 & 0.61 & $50.15-52.74$ & 51.55 & 0.56 \\
\hline
\end{tabular}

Table 2. Pearson correlation coefficient between HHV and elemental composition of sorghum biomass

\begin{tabular}{lcccccc}
\hline & HHV & Carbon & Hydrogen & Nitrogen & Sulfur & Oxygen \\
\hline HHV & 1 & $0.841^{* *}$ & 0.184 & $-0.476^{* *}$ & -0.052 & $-0.692^{* *}$ \\
Carbon & $0.841^{* *}$ & 1 & $0.248^{*}$ & $-0.527^{* *}$ & -0.034 & $-0.822^{* *}$ \\
Hydrogen & 0.184 & $0.248^{*}$ & 1 & $-0.274^{* *}$ & 0.001 & $-0.413^{* *}$ \\
Nitrogen & $-0.476^{* *}$ & $-0.527^{* *}$ & $-0.274^{* *}$ & 1 & $-.224^{*}$ & $0.435^{* *}$ \\
Sulfur & -0.052 & -0.034 & 0.001 & $-0.224^{*}$ & 1 & $-0.238^{*}$ \\
Oxygen & $-0.692^{* *}$ & $-0.822^{* *}$ & $-0.413^{* *}$ & $0.435^{* *}$ & $-0.238^{*}$ & 1 \\
\hline
\end{tabular}

** Correlation is significant at the 0.01 level (2-tailed).

* Correlation is significant at the 0.05 level (2-tailed).

Table 3. MLR coefficient results of HHV and elemental composition of sorghum

\begin{tabular}{llll}
\hline & Beta & t-values & p-values \\
\hline Constant & 6.175 & 6.725 & 0.000 \\
Carbon & 0.245 & 10.959 & 0.000 \\
Hydrogen & -0.027 & -0.478 & 0.633 \\
Nitrogen & -0.045 & -0.705 & 0.482 \\
Sulfur & -0.024 & -0.432 & 0.667 \\
Oxygen & -0.001 & -0.008 & 0.994 \\
\hline
\end{tabular}


Table 4. Model development for HHV

\begin{tabular}{|c|c|c|c|c|c|c|}
\hline & \multicolumn{3}{|c|}{ Full range $\left(4000-10000 \mathrm{~cm}^{-1}\right)$} & \multicolumn{3}{|c|}{ Reduced range $\left(6000-7000 \mathrm{~cm}^{-1}\right)$} \\
\hline & Spectra & $\begin{array}{c}\text { First } \\
\text { derivative }\end{array}$ & $\begin{array}{c}\text { Second } \\
\text { derivative }\end{array}$ & Spectra & $\begin{array}{c}\text { First } \\
\text { derivative }\end{array}$ & $\begin{array}{c}\text { Second } \\
\text { derivative }\end{array}$ \\
\hline \multicolumn{7}{|l|}{ PLS } \\
\hline $\mathrm{R}^{2}$, cal. & 0.83 & 0.82 & 0.83 & 0.95 & 0.99 & 0.90 \\
\hline $\mathrm{R}^{2}$, val. & 0.83 & 0.82 & 0.58 & 0.96 & 0.89 & 0.52 \\
\hline RMSEP & 0.112 & 0.118 & 0.174 & 0.061 & 0.089 & 0.188 \\
\hline RPD & 2.50 & 2.37 & 1.61 & 4.59 & 3.15 & 1.49 \\
\hline Factor used & 8 & 6 & 6 & 10 & 10 & 5 \\
\hline \multicolumn{7}{|l|}{ PCR } \\
\hline $\mathrm{R}^{2}$, cal. & 0.71 & 0.76 & 0.69 & 0.80 & 0.81 & 0.57 \\
\hline $\mathrm{R}^{2}$, val. & 0.57 & 0.71 & 0.49 & 0.85 & 0.78 & 0.44 \\
\hline RMSEP & 0.177 & 0.151 & 0.191 & 0.107 & 0.126 & 0.206 \\
\hline RPD & 1.58 & 1.85 & 1.47 & 2.62 & 2.22 & 1.36 \\
\hline PC used & 7 & 10 & 10 & 10 & 10 & 10 \\
\hline
\end{tabular}

Table 5. Model development for carbon content

\begin{tabular}{|c|c|c|c|c|c|c|}
\hline & \multicolumn{3}{|c|}{ Full range $\left(4000-10000 \mathrm{~cm}^{-1}\right)$} & \multicolumn{3}{|c|}{ Reduced range $\left(4362-7000 \mathrm{~cm}^{-1}\right)$} \\
\hline & Spectra & $\begin{array}{c}\text { First } \\
\text { derivative }\end{array}$ & $\begin{array}{c}\text { Second } \\
\text { derivative }\end{array}$ & Spectra & $\begin{array}{c}\text { First } \\
\text { derivative }\end{array}$ & $\begin{array}{c}\text { Second } \\
\text { derivative }\end{array}$ \\
\hline \multicolumn{7}{|l|}{ PLS } \\
\hline $\mathrm{R}^{2}$, cal. & 0.88 & 0.89 & 0.68 & 0.95 & 0.97 & 0.99 \\
\hline $\mathrm{R}^{2}$, val. & 0.88 & 0.90 & 0.46 & 0.96 & 0.83 & 0.20 \\
\hline RMSEP & 0.195 & 0.174 & 0.428 & 0.115 & 0.246 & 0.516 \\
\hline RPD & 3.03 & 3.39 & 1.38 & 4.69 & 2.40 & 1.14 \\
\hline Factor used & 10 & 7 & 4 & 8 & 8 & 9 \\
\hline \multicolumn{7}{|l|}{ PCR } \\
\hline $\mathrm{R}^{2}$, cal. & 0.71 & 0.73 & 0.72 & 0.91 & 0.81 & 0.52 \\
\hline $\mathrm{R}^{2}$,val. & 0.88 & 0.84 & 0.76 & 0.90 & 0.88 & 0.07 \\
\hline RMSEP & 0.227 & 0.241 & 0.293 & 0.184 & 0.199 & 0.573 \\
\hline RPD & 2.60 & 2.45 & 2.01 & 3.21 & 2.96 & 1.03 \\
\hline PC used & 9 & 10 & 10 & 10 & 10 & 10 \\
\hline
\end{tabular}


Table 6. Summary of preferred prediction models for hydrogen, nitrogen, sulfur, and oxygen contents

\begin{tabular}{lcccc}
\hline & Hydrogen & Nitrogen & Sulfur & Oxygen \\
\hline Quantitative method & PLS & PLS & PLS & PLS \\
& & & & \\
Pathlength type & MSC & SNV & SNV & SNV \\
& & & & \\
Spectral region & $4500-9800 \mathrm{~cm}^{-1}$ & $5000-5500 \mathrm{~cm}^{-1}$ & $4000-10000 \mathrm{~cm}^{-1}$ & $4500-8000 \mathrm{~cm}^{-1}$ \\
& & & & \\
Spectral treatment & none & none & none & first derivative \\
& & & & \\
$\mathrm{R}^{2}$, cal. & 0.93 & 0.88 & 0.87 & 0.83 \\
$\mathrm{R}^{2}$,val. & 0.87 & 0.86 & 0.84 & 0.83 \\
RMSEP & 0.072 & 0.084 & 0.063 & 0.166 \\
RPD & 2.52 & 2.98 & 2.38 & 3.37 \\
Factor used & 4 & 8 & 7 & 5 \\
\hline
\end{tabular}

